\title{
BMJ Open Quality Drugs associated with quality-related events reported by community pharmacies in Nova Scotia, Canada
}

\author{
Neil J MacKinnon (D , ${ }^{1}$ Adrian Boucher, ${ }^{2}$ James Barker, ${ }^{3}$ Certina $\mathrm{Ho}^{2}$
}

To cite: MacKinnon NJ, Boucher A, Barker J, et al. Drugs associated with quality-related events reported by community pharmacies in Nova Scotia, Canada. BMJ Open Quality 2020;9:e000853. doi:10.1136/ bmjoq-2019-000853

Received 14 0ctober 2019 Revised 27 March 2020 Accepted 12 May 2020
Check for updates

(C) Author(s) (or their employer(s)) 2020. Re-use permitted under CC BY-NC. No commercial re-use. See rights and permissions. Published by BMJ.

${ }^{1}$ Winkle College of Pharmacy, University of Cincinnati, Cincinnati, Ohio, USA

'Leslie Dan Faculty of Pharmacy, University of Toronto, Toronto, Ontario, Canada

${ }^{3}$ Faculty of Management, Dalhousie University, Halifax, Nova Scotia, Canada

Correspondence to Dr Neil J MacKinnon; rxdeanmac@uc.edu

\section{INTRODUCTION}

Twenty years since its publication, the Institute of Medicine's report, To Err is Human: Building a Safer Health System, ${ }^{1}$ has generated much attention towards identifying safety issues in healthcare. Quality-related events (QREs) are those medication incidents that reach the patient as well as incidents that are intercepted prior to dispensing. ${ }^{2}$

While considerable progress has been in documenting the magnitude of QREs in the inpatient setting, less is known about QREs in community pharmacy. In 2018, Campbell and colleagues coauthored a systematic review and meta-analysis of community pharmacy errors. ${ }^{3}$ Only nine studies met the inclusion criteria, the majority of which were of short duration (all but one were 40 weeks or less) and included a small number of prescriptions (all but one included less than 13000 prescriptions). Significant heterogeneity was identified among the studies.

To address this knowledge gap, we analysed QREs reported by community pharmacies in one Canadian province over a 7-year period and identified the drugs associated with harm.

\section{METHODS}

Since 2010, all community pharmacies in Nova Scotia, Canada have been required by the provincial pharmacy regulator to report all QREs anonymously to a national incident data repository (housed by the Institute for Safe Medication Practices Canada). ${ }^{4}$ QREs reported by all Nova Scotia community pharmacies from 1 October 2010 to 30 June 2017 were included in this retrospective analysis. A descriptive analysis was performed on QREs with respect to the drugs involved and whether the QREs resulted in harm. The Anatomical Therapeutic Chemical Classification System was used to classify the active ingredients of the drugs and to group them into categories for the purpose of this analysis. Patients and the public were not involved in the design of this study. A complete methodology description has been previously published. ${ }^{5}$

\section{RESULTS}

The 301 pharmacies in Nova Scotia reported 98097 QREs during the 7-year period. Of these QREs, almost 1\% (928) were associated with patient harm, where $90 \%$ (839 out of 928) were reported as mild harm. ${ }^{5}$

Levothyroxine sodium was the drug most commonly associated with a QRE, accounting for 2433 QREs or $2.34 \%$ of all QREs (table 1). It was closely followed by amoxicillin, which was reported in 2361 QREs or $2.27 \%$ of all QREs.

Levothyroxine sodium was the drug most commonly associated with a QRE causing harm (46 cases). Regarding levothyroxine, of the 46 harm cases, $44(96 \%)$ were reported as mild harm and $2(4 \%)$ were reported as moderate harm. Citalopram (27 cases), hydromorphone (25 cases) and warfarin (22 cases) were also commonly associated with harm. Together, these four drugs were responsible for $11.3 \%$ (120 out of 1064 cases) of all QREs that resulted in harm.

Table 2 displays the top 20 medications by proportion of QREs with harm (minimum of 10 QREs reported with harm). One in 10 $(10.33 \%)$ QREs reported with methadone resulted in harm, representing the greatest proportion of QREs with harm. Regarding methadone, of the 19 harm cases, 18 (95\%) were reported as mild harm and $1(5 \%)$ was reported as moderate harm. Methadone was followed by risperidone $(3.51 \%)$, warfarin $(2.95 \%)$ and morphine $(2.82 \%)$ as far as QRE cases associated with harm.

\section{DISCUSSION}

This study presents the first large-scale, longitudinal analysis of drugs associated with community pharmacy QREs in one 


\begin{tabular}{|c|c|c|}
\hline Medication & $\begin{array}{l}\text { ATC } \\
\text { classification }\end{array}$ & $\begin{array}{l}\text { Number (\%) of } \\
\text { QREs }\end{array}$ \\
\hline Levothyroxine sodium & H03AA01 & $2433(2.34)$ \\
\hline Amoxicillin & J01CA04 & $2361(2.27)$ \\
\hline Rosuvastatin & $\mathrm{C} 10 \mathrm{AA} 07$ & $1905(1.84)$ \\
\hline Lorazepam & N05BA06 & $1840(1.77)$ \\
\hline Hydromorphone & N02AA03 & $1826(1.76)$ \\
\hline Metoprolol & C07AB02 & $1786(1.72)$ \\
\hline Salbutamol & R03AC02 & 1745 (1.68) \\
\hline Metformin & A10BA02 & $1568(1.51)$ \\
\hline Rabeprazole & A02BC04 & $1459(1.41)$ \\
\hline Zopiclone & N05CF01 & $1374(1.32)$ \\
\hline Atorvastatin & C10AA05 & $1290(1.24)$ \\
\hline Citalopram & N06AB04 & $1261(1.21)$ \\
\hline Prednisone & $\mathrm{H} 02 \mathrm{AB} 07$ & 1254 (1.21) \\
\hline Naproxen & M01AE02 & $1236(1.19)$ \\
\hline Clonazepam & N03AE01 & $1175(1.13)$ \\
\hline $\begin{array}{l}\text { Codeine, combinations excl. } \\
\text { Psycholeptics }\end{array}$ & N02AA59 & $1163(1.12)$ \\
\hline Hydrochlorothiazide & С0ЗАА0З & $1158(1.12)$ \\
\hline Venlafaxine & $\mathrm{N} 06 \mathrm{~A} \times 16$ & $1143(1.10)$ \\
\hline Cefalexin & J01DB01 & $1127(1.09)$ \\
\hline Pantoprazole & A02BC02 & $1044(1.01)$ \\
\hline Total & - & $103812^{*}$ \\
\hline
\end{tabular}

*Total of all reported medications in QREs (excluding free-form entry of medication name). The reporter can input more than one medication per QRE; hence, the total number of QREs in this table is greater than what is shown in the results section.

ATC, Anatomical Therapeutic Chemical; QREs, quality-related events.

entire jurisdiction over an extended period of time. By identifying the drugs most commonly associated with QREs that result in harm, proactive strategies can be developed to reduce future events. When planning and prioritising quality improvement interventions in community pharmacy, it is important to consider the frequency and the severity of harm associated with the QREs.

Strengths of this study include the large number of QREs collected (nearly 100 000) over a 7-year period from all pharmacy types (independent, chain and so on) in every setting (urban, rural and so on) in one jurisdiction. Limitations include the small number of QREs causing harm, which precluded testing for differences across types of pharmacies or locations. Finally, Nova Scotia is a small province. Recently, other provinces have begun implementing new requirements for medication incident reporting in community practice, ${ }^{6}$ which could facilitate the completion of a larger analysis in the future. Nevertheless, this analysis provides valuable insight into the drugs associated with QREs in community pharmacy practice.

Twitter Neil J MacKinnon @RxDeanMac
Table 2 Top 20 medications by proportion of QREs with harm (minimum of 10 QREs reported with harm)

\begin{tabular}{llrrr}
\hline Medication & $\begin{array}{l}\text { ATC } \\
\text { classification }\end{array}$ & $\begin{array}{l}\text { Number (\%) } \\
\text { of QREs with } \\
\text { harm }\end{array}$ & $\begin{array}{l}\text { Number (\%) of } \\
\text { QREs }\end{array}$ & $\begin{array}{l}\text { Proportion } \\
\text { of QREs with } \\
\text { harm (\%) }\end{array}$ \\
\hline Methadone & N07BC02 & $19(1.79)$ & $184(0.18)$ & 10.33 \\
\hline Risperidone & N05A×08 & $11(1.03)$ & $313(0.30)$ & 3.51 \\
\hline Warfarin & B01AA03 & $22(2.07)$ & $746(0.72)$ & 2.95 \\
\hline Morphine & N02AA01 & $16(1.50)$ & $568(0.55)$ & 2.82 \\
\hline Atenolol & C07AB03 & $14(1.32)$ & $544(0.52)$ & 2.57 \\
\hline Citalopram & N06AB04 & $27(2.54)$ & $1261(1.21)$ & 2.14 \\
\hline $\begin{array}{l}\text { Norgestimate and } \\
\text { oestrogen }\end{array}$ & G03AB11 & $10(0.94)$ & $528(0.51)$ & 1.89 \\
\hline Levothyroxine sodium & H03AA01 & $46(4.32)$ & $2433(2.34)$ & 1.89 \\
\hline Gliclazide & A10BB09 & $13(1.22)$ & $694(0.67)$ & 1.87 \\
\hline Ramipril & C09AA05 & $14(1.32)$ & $778(0.75)$ & 1.80 \\
\hline $\begin{array}{l}\text { Sulfamethoxazole and } \\
\text { trimethoprim }\end{array}$ & J01EE01 & $13(1.22)$ & $808(0.78)$ & 1.61 \\
\hline Furosemide & C03CA01 & $15(1.41)$ & $1024(0.99)$ & 1.46 \\
\hline Hydromorphone & N02AA03 & $25(2.35)$ & $1826(1.76)$ & 1.37 \\
\hline Venlafaxine & N06A×16 & $14(1.32)$ & $1143(1.10)$ & 1.22 \\
\hline Amlodipine & C08CA01 & $12(1.13)$ & $988(0.95)$ & 1.21 \\
\hline Sertraline & N06AB06 & $10(0.94)$ & $845(0.81)$ & 1.18 \\
\hline Naproxen & M01AE02 & $13(1.22)$ & $1236(1.19)$ & 1.05 \\
\hline Prednisone & A02BA07 & $13(1.22)$ & $1254(1.21)$ & 1.04 \\
\hline Pantoprazole & $10(0.94)$ & $1044(1.01)$ & 0.96 \\
\hline Rosuvastatin & C10AA07 & $18(1.69)$ & $1905(1.84)$ & 0.94 \\
\hline & - & $1064^{*}$ & $103812 \dagger$ & - \\
\hline Total & & & & \\
\hline
\end{tabular}

"Total of all reported medications in QREs with harm (excluding free-form entry of medication name); the reporter can input more than one medication per QRE; hence, the total number of QREs associated with patient harm in this table is greater than what is shown in the results section.

Total of all repors is 作

ATC, Anatomical Therapeutic Chemical; QREs, quality-related events.

Acknowledgements The authors acknowledge the Institute for Safe Medication Practices Canada for providing access to the anonymously reported quality-related events by Nova Scotia community pharmacies that made this study possible and the SafetyNET-Rx Research Team.

Contributors $\mathrm{AB}$ and $\mathrm{CH}$ contributed substantially to the concept and design, acquisition of data, analysis and interpretation of data and provided input into the draft manuscript. JB contributed substantially to the analysis and interpretation of data, revised the manuscript critically for important intellectual content and obtained the funding. NM contributed substantially to the conception and design, the analysis and interpretation of data and wrote the first draft of the manuscript.

Funding This study was funded by The Kenneth C. Rowe Gift, Rowe School of Business, Dalhousie University, Halifax, NS, Canada.

Competing interests None declared.

Patient and public involvement Patients and/or the public were not involved in the design, or conduct, or reporting, or dissemination plans of this research.

Patient consent for publication Not required.

Provenance and peer review Not commissioned; externally peer reviewed.

Data availability statement Data may be obtained from a third party and are not publicly available.

Open access This is an open access article distributed in accordance with the Creative Commons Attribution Non Commercial (CC BY-NC 4.0) license, which permits others to distribute, remix, adapt, build upon this work non-commercially, and license their derivative works on different terms, provided the original work is properly cited, appropriate credit is given, any changes made indicated, and the use is non-commercial. See: http://creativecommons.org/licenses/by-nc/4.0/.

ORCID iD

Neil J MacKinnon http://orcid.org/0000-0001-8111-6651 


\section{REFERENCES}

1 Kohn LT, Corrigan JM, Donaldson MS. To err is human: building a safer health system. Washington (DC): National Academies Press, 1999.

2 Boyle TA, Bishop AC, Duggan K, et al. Keeping the "continuous" in continuous quality improvement: exploring perceived outcomes of CQI program use in community pharmacy. Res Social Adm Pharm 2014;10:45-57.

3 Campbell PJ, Patel M, Martin JR, et al. Systematic review and metaanalysis of community pharmacy error rates in the USA: 1993-2015. BMJ Open Qual 2018;7:e000193.
4 Nova Scotia College of Pharmacists. Standards of practice: continuous quality assurance programs in community pharmacies. Halifax: Nova Scotia College of Pharmacists, 2019.

5 Boucher A, Ho C, MacKinnon N, et al. Quality-Related events reported by community pharmacies in nova Scotia over a 7-year period: a descriptive analysis. CMAJ Open 2018;6:E651-6.

6 MacKinnon NJ, Cook R, Barker JR. Expansion of patient safety regulatory requirements in community pharmacy in Canada: the Melissa Sheldrick effect? Can Pharm J 2019;152:77-80. 